\title{
Os adultos e suas escritas pré-alfabéticas
}

\section{Adults and their pre-alphabetic writing's}

Paula Takada é professora e jornalista. Mestre em Comunicação Social pela Umesp, especialista em Alfabetização pelo Instituto Vera Cruz, graduada em Jornalismo pela Universidade de São Paulo e em Pedagogia pela Universidade Nove de Julho. É professora polivalente da Escola Vera Cruz e de professora de Jornalismo do Colégio Stockler. Atuou como formadora de professores na Comunidade Educativa Cedac e foi editora do site da revista Nova Escola.

\section{Contato: patakada@gmail.com}

\section{Resumo}

Este artigo é uma síntese de um estudo' no qual analisamos as soluções utilizadas por adultos não alfabéticos na tarefa de escrever e interpretar uma lista de palavras escritas com lápis sobre papel e, em seguida, no computador. Encontramos a produção de escritas silábico-alfabéticas compostas por escritas silábicas justapostas, uso de letras com a função de recheio gráfico, uso de letras como coringa, hipótese do nome da sílaba e alternâncias grafo-fônicas, desordens com pertinências, tal como verificado por Molinari (2007), Quinteros (1997) e Ferreiro (2009).

Palavras-chave: Alfabetização. Adultos. Analfabetismo funcional. Alternâncias grafo-fônicas.
Abstract
This study analyzed the solutions used by not literate adults during the tasks of writing and interpreting a list of words written with pencil on paper, and then on the computer. We faced the production of syllabic-alphabetic writings composed by juxtaposed syllabic writings, use of letters with the purpose of graphic filling, use of letters in a multifunctional way, syllable name hypothesis and

1. Tal estudo de caso integrou a monografia de conclusão do curso de pós-graduação "Alfabetização: relações de ensino entre aprendizagem", no Instituto Superior de Educação Vera Cruz, em 2012, sob a orientação da Profa. Dra. Telma Weisz. 
grapophonic alternations, writing disability, as observed by Molinari (2007), Quinteros (1997) and Ferreiro (2009). Keywords: Literacy. Adults. Functional illiteracy. Graphicalphonic alternations.

\section{Introdução}

Alguns estudaram poucos anos durante a infância em uma cidade diferente da que estão agora. Outros nunca estudaram, mas, depois de adultos, buscaram a alfabetização em escolas regulares ou projetos sociais vinculados a associações de bairro ou organizações não governamentais. Há ainda aqueles que nunca estudaram, nem na infância nem quando adultos. De um jeito ou de outro, esses sujeitos possuem diferentes ideias sobre o funcionamento da língua escrita - e esse saber não está diretamente relacionado à experiência escolar. Ou seja, os adultos possuem certos conhecimentos e hipóteses acerca de como funciona a língua escrita, ainda que não a dominem completamente. Esses conhecimentos foram incorporados pelas vivências escolares e extra-escolares que tiveram na infância e na idade adulta. São, portanto, saberes bastantes distintos e mesclam as variadas contribuições típicas de uma vida imersa em uma cultura letrada, influenciada por experiências como a leitura da Bíblia, o acesso aos meios de comunicação, as placas nas ruas, os letreiros de ônibus, trens, além da convivência com filhos e netos em idade escolar que levam para casa certo contato com a língua escrita. Toda essa multiplicidade de fontes de conhecimento sobre a leitura e a escrita confere um saber também múltiplo e, muitas vezes, "estranho" aos olhares de um adulto convencionalmente alfabetizado.

Com relação às semelhanças e diferenças entre adultos e crianças no processo de aquisição da língua escrita, Ferreiro conclui:

\footnotetext{
(...) los adultos manifestan los mismos requerimientos de cantidad mínima y de variedad interna que ya conocemos en los niños; manifestan similar distinción entre 'lo que está escrito' y 'lo que se puede leer', dificultades similiares para manejar las relaciones entre el todo y las partes al nivel de la palabra escrita; etc. Pero también es cierto que no todos los niveles de conceptualización identificados en los niños se reencuentran en los adultos: los niveles más primitivos están prácticamente ausentes. (FERREIRO, 1983, p. 143)
} 
Investigações realizadas nas últimas décadas no campo da psicogênese da língua escrita têm esclarecido os detalhes do complexo caminho percorrido por crianças na aquisição do sistema alfabético de escrita. Orientadas por Ferreiro, as pesquisadoras Claudia Molinari (2007) e Graciela Quinteros (1997) observaram e categorizaram as soluções pontuais empreendidas por crianças de 4 a 5 anos que se encontravam na transição entre uma hipótese silábica e uma concepção alfabética de escrita. Encontraram, dessa maneira, escritas silábico-alfabéticas compostas por escritas silábicas justapostas, uso de letras com a função de recheio gráfico, uso de letras como coringa, hipótese do nome da sílaba, alternâncias grafo-fônicas e desordens com pertinências.

Mas e os adultos não alfabetizados? Que soluções utilizam durante o período de transição entre uma hipótese silábica de escrita e uma hipótese silábico-alfabética? Quais são as semelhanças e as diferenças entre as escritas dos adultos e as das crianças nesse momento em que possuem uma hipótese silábicoalfabética? Essas foram as principais questões que orientaram nosso estudo.

Analisamos as escritas de seis sujeitos adultos não alfabetizados que realizaram a tarefa de escrever e interpretar uma lista de palavras, primeiramente com lápis sobre o papel e, em seguida, no computador. Realizamos também entrevistas semiestruturadas para compor o perfil desses adultos, priorizando o histórico que tiveram com a escola e os estudos. Todas as tarefas e entrevistas foram protocoladas em vídeo.

\section{Referencial teórico}

\subsection{As soluções pontuais presentes nas escritas silábico- -alfabéticas}

Observando crianças com idade entre 4 e 7 anos e que escreviam segundo a hipótese silábica ou silábico-alfabética, Graciela Quinteros (1997) e Claudia Molinari (2007) - ambas orientadas por Emilia Ferreiro - encontraram algumas regularidades entre as escritas analisadas.

Foram as análises detalhadas de processos de escritas produzidas por crianças como Maria, de 5 anos, que ajudaram a esclarecer algumas particularidades da escrita silábico-alfabética. Ao escrever "sopa", a menina produz primeiramente uma escrita tipicamente silábica "OA". Insatisfeita com a quantidade de letras - já que nessa fase as crianças acreditam que seja necessário 
no mínimo três ou quatro letras para garantir que a escrita seja legível - completa sua escrita, agregando "SP". O resultado final é "OASP". "Todas as letras da palavra estão ali, mas em desordem, (...) 0 que Maria produz são duas escritas silábicas justapostas", pontua Ferreiro (2009).

Soluções curiosas como a de Maria foram observadas por Graciela Quinteros, em 1997, durante sua pesquisa de mestrado, no México. Ela notou que crianças com hipótese silábica usavam algumas letras com funções específicas que não a de corresponder ao som da sílaba propriamente dito. Graciela encontrou, dessa maneira, letras sendo usadas com três diferentes funções, a saber:

a) Uso de letras com a função de recheio gráfico: uso de uma ou mais letras para separar graficamente vogais iguais ou para preencher um espaço dentro ou ao final da palavra. Conforme explica Quinteros:

Este tipo de solución es interesante, porque el niño utiliza letras con una
función diferente, no alfabética. Esta solución original no es absurda ya
que nuestro sistema también tiene componentes ideográficos que no
necesariamente se leen. Se llamará a tal función de las letras, relleno
gráfico, y se caracterizará como un intento de completar una configuración
con el único objetivo de que la misma esté bien escrita y sea algo 'legible'
Los valores sonoros de dichas letras no son tomados en cuenta porque no
se colocan para representar ningún aspecto oral (QUINTEROS, 1997, p. 22).

Vejamos alguns exemplos observados por Quinteros em língua espanhola, nas escritas de Sergio ( 6 anos), que utiliza sistematicamente a letra " $\mathrm{H}$ " com a função de recheio gráfico separador:

Tabela 1 - 0 uso da letra "H" com a função de recheio gráfico.

\begin{tabular}{|c|c|}
\hline ZAPATO & saHao \\
\hline LUZ & uHus \\
\hline GOL & oHo \\
\hline MIEL & ieHe \\
\hline
\end{tabular}

b) Uso de letras com a função de coringa: emprego de uma letra para substituir uma sílaba ou uma consoante que a criança reconhece que deve ser grafada, mas não sabe como. Geralmente, uma mesma letra aparece como coringa em várias palavras. No exemplo abaixo, Elva ( 6 anos) escreve ferrocarril (que significa "ferrovia" em espanhol): 
Tabela 2 - 0 uso da letra "Y" com a função de coringa.

\begin{tabular}{|l|l|}
\hline FERROCARRIL & Ye o Q i \\
\hline
\end{tabular}

\begin{abstract}
La presencia de la sílaba [fe] en el inicio de esta palabra motiva Elva a incorporar $\{\mathrm{Y}\}$ como comodín silábico: la niña dice [fe] ?cuál es la [fe]? Elva no se permite colocar cualquier letra consonántica con valor sonoro como comodín: al querer usar $\{D\}$ dice: 'no, esa no es [fe] es [de]'. Al buscar dicho comodín, Elva se da cuenta de la necesidad de marcar el aspecto vocálico, y entonces agrega una vocal. Finalmente, el comodín, 'la ye' se convirte en una letra sustituta intrasilábica para marcar un aspecto consonántico, su valor deja de ser silábico (QUINTEROS, 1997, p. 52).
\end{abstract}

c) Uso de letras de acordo com a hipótese do nome da sílaba: quando as crianças, apoiadas no conhecimento do nome da letra, usam-na para escrever uma sílaba inteira. São comuns os usos do "K" para "ca", do "P" para "pê", do "H" para "ga" e assim por diante.
Quizá los niños piensen que: si existen letras consonantes con nombres silábicos, (la ka, la pe, la be) deben existir nombres silábicos que se corresponden con letras consonánticas que conocen por su forma pero no por su valor sonoro (QUINTEROS, 1997, p. 39).

No exemplo abaixo, Elva usa a letra "T" para grafar a sílaba "te", em mantequilla (que significa "manteiga" em espanhol):

Tabela 3 - 0 uso da letra "t" de acordo com a hipótese do nome da sílaba.

\begin{tabular}{|l|l|}
\hline MANTEQUILLA & $\mathbf{m} \mathbf{t} \mathrm{ja}$ \\
\hline
\end{tabular}

\title{
1.2. Alternâncias grafo-fônicas e desordem com pertinência
}

Com base nessas descobertas, Claudia Molinari, em 2007, também durante sua pesquisa de mestrado, observou crianças realizando a tarefa de escrever consecutivamente uma mesma lista, primeiramente com lápis sobre o papel e, em seguida, no computador. Focou a análise, portanto, em pares de palavras, o que evidenciou escritas intrigantes como as de Santiago, de 5 anos. Ao escrever "soda", no papel, produziu "AS", e, no computador, "OD". Para "salame", escreveu "SAM", no papel, e "ALE", no computador. "Por que, se Santiago conhece todas as letras de 'soda' e de 'salame', não pode colocá-las juntas? Temos chamado esse fenômeno de alternâncias grafo-fônicas", indica Ferreiro (2009). 
Molinari distingue três tipos de alternâncias grafo-fônicas: de $1 / 1$, de $2 / 1$ ou $1 / 2$ e ortográficas. Vejamos como se caracteriza cada uma delas.

\section{a) Alternâncias grafo-fônicas $1 / 1$}

De acordo com Molinari (2007), é possível identificar um primeiro tipo de alternância grafo-fônica em que uma mesma sílaba é grafada, primeiramente com uma única das letras possíveis e, em seguida, com outra letra possível (alternância grafo-fônica de uma letra para outra letra, ou 1/1):

En las escrituras silábico estrictas Ilamaremos alternancia grafo-fónica a la escritura sucesiva de un segmento silábico de la misma palabra con letras pertinentes, pero tales que, de las posibles letras de una sílaba, aparece solo una de ellas en una primera realización, y solo otra en una segunda realización. Estas letras presentan valores sonoros idénticos pero con realizaciones gráficas alternativas. Tenemos, pues, un caso paradojal de identidad fónica (silábica) sin identidad g'áfica (MOLINARI, 2007, p. 55).

\section{b) Alternâncias grafo-fônicas $2 / 1$ ou $1 / 2$}

Molinari (2007) também identificou um segundo tipo de alternância grafo-fônica mais frequente em escritas de crianças silábico-alfabéticas:

\footnotetext{
En estas producciones silábico-alfabéticas llamaremos alternancias grafofónicas a la escritura sucesiva en el tiempo de un segmento silábico de la misma palabra con letras pertinentes, pero tales que, de las posibles letras de una sílaba, aparece solo una de ellas en una primera realización y más de una en una segunda realización (o a la inversa). Lo importante es que los niños que producen estas alternancias pueden considerar elementos intrasilábicos, pero se trata de coordinaciones momentáneas sin estabilidad. Están renunciando a la regla anterior de una sola letra por sílaba, pero no son aún capaces de sostener un análisis consistente de todas las sílabas (MOLINARI, 2007, p. 61).
}

\section{c) Alternâncias grafo-fônicas ortográficas}

Finalmente, há um terceiro tipo de alternância grafo-fônica identificado por Molinari (2007), as alternâncias grafo-fônicas ortográficas:

Llamaremos alternancias grafo-fónicas ortográficas a la escritura sucesiva (en el tiempo) de un segmento silábico de la misma palabra con letras pertinentes, pero tales que, de sus posibles opciones ortográficas 
(convencionales o no), aparece una de ellas en una primera realización y otra en una segunda realización (ejemplos [en español] K/C, V/B, C/S). Los niños están introduciendo valores ortográficos alternativos, en tanto opciones a disposición, sin estabilidad (MOLINARI, 2007, p. 65).

Ferreiro (2009) analisa essa situação, comparando a análise das sílabas pela criança com a escuta de um acorde musical por um leigo em música que não consegue distinguir os instrumentos que o compõem:

\begin{abstract}
Da centração privilegiada nas vogais (as cordas que vibram) se passa a escutar o mesmo acorde musical desde outros instrumentos (não vogais). São centrações alternadas, incompatíveis entre si: uma ou outra, porém não as duas de uma vez. Parece-me que as crianças escutam a sílaba como se fosse um acorde musical produzido por vários instrumentos. É a escrita que obriga a considerar esses sons simultâneos como se fossem sucessivos (FERREIRO, 2009, p. 10).
\end{abstract}

Essas soluções de compromisso encontradas por Ferreiro, Molinari e Quinteros nos servirão de categorias para classificar as escritas produzidas pelos adultos entrevistados nesta pesquisa.

\title{
2. Metodologia
}

Por meio do método clínico, observamos a realização da tarefa de escrever e interpretar a própria escrita de uma lista de palavras ditadas, interrogando o entrevistado ou solicitando alguma justificativa quando necessário. Para reconstituir parte da trajetória de vida dos sujeitos - com foco em sua relação com a leitura, a escrita e a escola - utilizamos a entrevista semiestruturada. Todo o processo foi gravado em vídeo, o que permitiu que observássemos diversas vezes o percurso até chegar a uma determinada escrita e sua leitura - e não apenas o produto final registrado.

\subsection{Caracterização da amostra: os sujeitos da pesquisa}

Foram entrevistados 25 adultos individualmente, no período de 21 de agosto de 2011 a 10 de janeiro de 2012. Primeiramente, realizamos uma entrevista-teste com o objetivo de identificar os sujeitos com hipóteses próximas à silábica com valor sonoro convencional ou silábico-alfabética. Encontramos 14 adultos que já apresentavam uma escrita alfabética, dois com hipótese silábica sem valor sonoro convencional e três pré-silábicos. Houve também três adultos que apresentaram escritas silábicas com valor sonoro 
convencional e três com escritas silábico-alfabéticas. Esses seis últimos, portanto, constituem a amostra de nosso estudo.

Dos 25 entrevistados, uma era moradora da favela do Jardim Panorama, quatro eram da favela do Real Parque, seis residiam na favela do Paraisópolis, nove moravam na Vila $1^{\circ}$ de Outubro, em Guaianazes, e cinco frequentavam um projeto de alfabetização de adultos não formal em uma associação cultural que funcionava dentro da Companhia de Entrepostos e Armazéns Gerais de São Paulo (Ceagesp). Havia 14 mulheres e 11 homens, com idades que variavam de 30 a 82 anos.

\subsection{Procedimentos para a coleta de dados}

$\mathrm{Na}$ entrevista-teste propusemos a tarefa de escrita de uma lista de palavras que foram ditadas para que escrevessem da melhor maneira que conseguissem. As palavras dessa primeira lista pertenciam ao campo semântico da construção civil (betoneira, cimento, pedra, areia, água, pá).

Com as seis pessoas da amostra, complementamos a entrevista-teste com a escrita de uma outra lista composta por palavras do campo dos alimentos que podem ser encontrados em uma feira (tapioca, tomate, caqui, peixe, pera, figo, uva). Cada entrevistado escreveu essa segunda lista duas vezes, na mesma sessão: primeiramente, com lápis no papel e, em seguida, no computador. A cada palavra, pedíamos para a pessoa ler o que havia acabado de escrever, indicando com o dedo onde estava lendo, esclarecendo algumas dúvidas à entrevistadora quando necessário. Não houve nenhuma ajuda aos sujeitos durante a realização das tarefas.

As listas de palavras foram formadas segundo os critérios de quantidade de sílabas (uma polissílaba, uma trissílaba e cinco dissílabas), evitando-se palavras com sons nasais e considerando o campo semântico familiar aos entrevistados. Selecionamos mais dissílabas porque são elas que apresentam aos sujeitos com hipótese silábica estrita um conflito a resolver: o desafio de conciliar uma exigência qualitativa de usar uma letra com valor sonoro para cada sílaba - "sem omitir sílabas e sem repetir letras" (FERREIRO, 1988, p. 25) - e uma exigência quantitativa de usar pelo menos três letras (ou, às vezes, quatro) para garantir legibilidade à palavra. Com mais palavras, é possível analisar melhor como os adultos lidam com esses registros. 
As palavras foram ditadas e repetidas quando necessário. Quando erravam, deveriam reescrever a palavra na linha abaixo, corrigindo o que se desejava. Esse mesmo procedimento foi adotado no computador. Dessa maneira, todas as tentativas de escrita permaneceram registradas. Inicialmente, a lista era escrita no papel e, depois, no computador, sem que a pessoa pudesse consultar a primeiro registro. No computador, utilizou-se a fonte Arial, tamanho 28, fixada em caixa alta.

As escritas produzidas pelos seis adultos serão abordadas de duas maneiras. Com base no trabalho de Quinteros (1997), buscaremos replicar a análise que a pesquisadora fez do processo e do resultado final da cada uma das palavras escritas pelos sujeitos. Será uma abordagem voltada para o interior de cada uma das palavras produzidas. Na sequência, utilizaremos como base a pesquisa de Molinari (2007) para realizar um estudo com foco nos pares de palavras, comparando as duas escritas de um mesmo termo - primeiramente com lápis sobre o papel e, em seguida, no computador. Teremos, portanto, duas análises: uma intra palavras e outra entre palavras.

Ao todo, foram produzidas 110 palavras (55 pares).

\section{Análises dos dados}

Antes de analisar o processo de escrita dos sujeitos entrevistados neste estudo, é preciso ponderar uma primeira diferença nítida entre as escritas desses adultos não alfabetizados e as das crianças que frequentam a escola. Compõem nossa amostra escritas bastante confusas, o que significa que as hipóteses dessas pessoas não são tão evidentes. Não são "escritas de manual de alfabetização". Encontramos a coexistência de concepções "avançadas" - como a escrita silábica com valor sonoro convencional ou silábico-alfabética - com noções muito precárias acerca da grafia de todas as letras do alfabeto, por exemplo.

Foi o que ocorreu com Benedita, Eliane e Josefa, que não dominavam a grafia convencional de todas as letras. Para escrever a lista de palavras, empregavam principalmente as vogais e as consoantes que pertencem ao nome e sobrenome delas.

Josefa produziu as melhores escritas para exemplificar essa coexistência de concepções básicas e avançadas em uma mesma palavra. Ao escrever "tomate" à mão, grafou um " $T$ " que parecia 
um " $F$ " incompleto ou um "L" de ponta-cabeça (Г) - desenho, aliás, muito semelhante a um "T" convencional, como é possível verificar na Figura 1.

Figura 1 - reprodução da escrita de Josefa para a palavra "tomate".

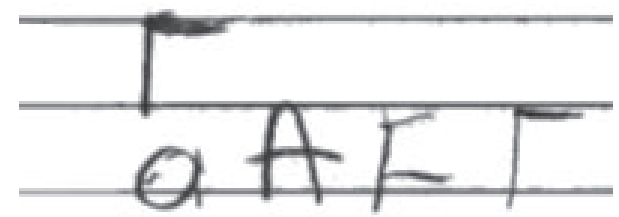

Sabemos que sua intenção era escrever a letra "T", porque perguntamos a ela que letra era aquela que acabara de escrever. Josefa confirmou: "É um T". Antes de escrever "caqui", falou: "Cáá - qui, é o ca de Karina". E grafou um "H". A escrita de "caqui" resulta em "HIHI".

Essas escritas mais enigmáticas dos adultos não alfabetizados são, a um só tempo, avançadas em relação à correspondência de alguma forma gráfica a um fonema, mas não avançadas em relação a como se grafam convencionalmente algumas letras. Escritas como a de Josefa poderiam ser classificadas como silábicas com valor sonoro convencional, nem sempre com grafia convencional.

Temos observado que a presença de escritas desse tipo não se limita aos sujeitos entrevistados, sendo utilizadas por muitos adultos não alfabetizados. Observamos também que parte desse público que está tentando se alfabetizar - seja nas escolas regulares, seja em projetos sociais - é considerada pré-silábica, por seus professores, apenas por não apresentar uma grafia convencional das letras, enquanto, na realidade, já descobriram que a cada som falado deve corresponder uma marca gráfica, tendo, portanto e pelo menos, uma hipótese silábica com falha no valor sonoro convencional.

\subsection{Análise intra palavras}

Começaremos a análise dos dados coletados, observando a escrita de cada palavra. Primeiramente, vamos identificar as escritas que usam as mesmas soluções pontuais encontradas por Quinteros (1997) na pesquisa com crianças, a saber: uso de letras com a função de recheio gráfico, uso de letras com a função de coringa (silábico ou de letra), uso da letra de acordo com a 
hipótese do nome da sílaba. Observaremos também a ocorrência das escritas silábicas justapostas (FERREIRO, 2009). Em algumas palavras encontramos a ocorrência de mais de uma solução pontual ao mesmo tempo.

\subsubsection{Uso de letras com a função de recheio gráfico}

Em 15 palavras, encontramos uma letra ou um conjunto de letras sendo usados com a função de recheio gráfico. Esse tipo de solução foi empregada por três entrevistadas (Benedita, Eliane e Josefa). Seguem alguns exemplos:

Tabela 4 - Exemplos de uso de letras com a função de recheio gráfico.

\begin{tabular}{|c|c|}
\hline \multicolumn{2}{|c|}{ Uso de letras com a função de recheio gráfico } \\
\hline Benedita (escrita manual) & 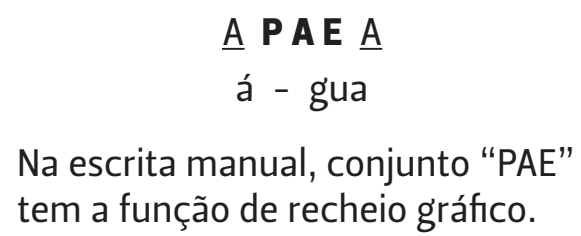 \\
\hline Benedita (escrita no computador) & $\begin{array}{l}\qquad \frac{\mathrm{A} \text { I A }}{\text { água }} \\
\text { No computador, o recheio fica } \\
\text { restrito à letra "I". }\end{array}$ \\
\hline Eliane (escrita manual) & $\begin{array}{l}\qquad \frac{P \text { R T A }}{\text { pe }- \text { ra }} \\
\text { Uso da letra "T" como recheio } \\
\text { gráfico. }\end{array}$ \\
\hline Eliane (no computador) & $\begin{array}{l}\qquad \frac{\mathrm{P} \text { R N A }}{\text { pe }- \text { ra }} \\
\text { Uso da letra "N" como recheio } \\
\text { gráfico. }\end{array}$ \\
\hline Josefa (escrita manual) & $\begin{array}{l}\qquad \underline{A P} \underline{A} \\
a-\text { u - va } \\
\text { Uso da letra "A" como recheio } \\
\text { gráfico. }\end{array}$ \\
\hline
\end{tabular}

\subsubsection{Uso de letras com a função de coringa}

Em 17 palavras, encontramos uma ou mais letras utilizadas com a função de coringa silábico (para representar uma sílaba inteira) 
ou de coringa consonantal (para representar uma consoante). Chamamos atenção para a ocorrência do uso de consoantes como coringa vocálico, ou seja, para representar uma vogal em seis palavras. Dos seis entrevistados, cinco empregaram letras com função de coringa em suas escritas.

Tabela 5 - Exemplos de uso de letras com a função de coringa.

\begin{tabular}{|c|c|}
\hline \multicolumn{2}{|r|}{ Uso de letras com a função de coringa } \\
\hline $\begin{array}{c}\text { Anália } \\
\text { (escrita manual) }\end{array}$ & $\begin{array}{l}\text { C O MEA I } \\
\text { to - ma - te } \\
\text { A letra "C" tem função de coringa consonantal, representando o } \\
\text { "T". }\end{array}$ \\
\hline $\begin{array}{c}\text { Benedita } \\
\text { (escrita manual) }\end{array}$ & $\begin{array}{l}\frac{\text { FI }}{\mathrm{A} O} \\
\mathrm{fi}-\text { go } \\
\text { "A" usado como coringa consonantal para representar a letra "g". }\end{array}$ \\
\hline $\begin{array}{c}\text { Eliane } \\
\text { (escrita manual) }\end{array}$ & $\begin{array}{l}\underline{\text { B }} \underline{\text { TO }} \underline{\mathbf{R}} \underline{\mathrm{A}} \\
\text { bi -tor - ne - rea } \\
\text { "R" usado como coringa silábico para representar a sílaba "ne". }\end{array}$ \\
\hline $\begin{array}{c}\text { Eliane } \\
\text { (escrita manual) }\end{array}$ & $\begin{array}{l}\underline{\text { TR I I A }} \\
\text { ta - pio - ca } \\
\text { "R" usado como coringa vocálico para representar a letra "a", e o } \\
\text { "T" usado como coringa consonantal para representar a letra "c". }\end{array}$ \\
\hline $\begin{array}{c}\text { Eliane } \\
\text { (no computador) }\end{array}$ & $\begin{array}{l}\text { I } \underline{\mathbf{R}} \underline{\mathrm{A}} \\
\text { ta - pio - ca } \\
\text { "R" usado como coringa silábico para representar a sílaba "pio". }\end{array}$ \\
\hline $\begin{array}{c}\text { Rosevaldo } \\
\text { (no computador) }\end{array}$ & $\begin{array}{l}\underline{Q} \underline{\underline{A}} \\
\text { u-ve-a, uva } \\
\text { Grafou o Q, mas chamou de U. } \\
\text { "Q" usado como coringa vocálico para representar a letra "u". }\end{array}$ \\
\hline
\end{tabular}

\subsubsection{Uso de letras de acordo com a hipótese do nome da sílaba}

Em 23 palavras, encontramos as letras "B", "P", "T", "K" e "H" sendo usadas de acordo com a hipótese do nome da sílaba. Em alguns casos, as letras "N" e "R" também foram identificadas 
dentro desse tipo de uso, já que os entrevistados as nomeiam respectivamente de "nê" e "rê". Todos os entrevistados usaram letras de acordo com a hipótese do nome da sílaba, pelo menos uma vez.

Tabela 6 - Exemplos de uso de letras de acordo com a hipótese do nome da sílaba.

\begin{tabular}{|c|c|}
\hline \multicolumn{2}{|c|}{ Uso de letras de acordo com a hipótese do nome da sílaba } \\
\hline Anália (no computador) & $\begin{array}{l}\underline{\text { TO }} \underline{\mathbf{M}} \underset{\mathbf{I}}{\text { to }- \text { ma - te }} \\
\text { "T" usado para representar a sílaba toda "te". }\end{array}$ \\
\hline Benedita (escrita no computador) & $\begin{array}{l}\text { B } \underline{\text { II }} \mathbf{\underline { N }} \underline{\text { A }} \\
\text { be -to - ne - ra } \\
\text { O "B" está sendo usado para representar a sílaba } \\
\text { toda "be". "N" está sendo usado para represen- } \\
\text { tar a sílaba "ne", considerando que a entrevista- } \\
\text { da nomeia a letra "N" como "nê". }\end{array}$ \\
\hline Elaine (escrita manual) & $\begin{array}{l}\text { P RTA } \\
\text { pe - ra } \\
\text { "P" usado para representar a sílaba toda "pe". }\end{array}$ \\
\hline Josefa (no computador) & $\begin{array}{l}\underline{P} \underline{\mathbf{P}} \underline{\underline{\mathbf{X}}} \\
\text { pe - pe - } \mathrm{i}-\mathrm{xis}, \text { pexi } \\
\text { "P" usado para representar a sílaba toda "pe", e } \\
\text { "X" para representar "xi". }\end{array}$ \\
\hline Lourivaldo (escrita manual) & $\begin{array}{l}\frac{\text { VI }}{\text { ve-i-vi g gue-a-gá, viga }} \\
\text { "H" usado para representar a sílaba "ga" (apesar } \\
\text { de ela já estar escrita). }\end{array}$ \\
\hline Rosevaldo (no computador) & $\begin{array}{l}\underline{B} \underline{\underline{N}} \underline{\underline{N} \text { A }} \\
\text { bi -to - ne- ra } \\
\text { "N" usado para representar a sílaba "ne", con- } \\
\text { siderando que a entrevistada nomeia a letra "N" } \\
\text { como "nê". }\end{array}$ \\
\hline Rosevaldo (escrita no computador) & $\begin{array}{l}\underline{I} \underline{\mathrm{M}} \underline{\mathbf{I}} \\
\text { to - ma - te } \\
\text { "T" usado para representar a sílaba toda "te". }\end{array}$ \\
\hline
\end{tabular}




\begin{tabular}{|c|c|}
\hline \multicolumn{2}{|c|}{ Uso de letras de acordo com a hipótese do nome da sílaba } \\
\hline Rosevaldo (no computador) & $\begin{array}{l}\underline{\mathbf{K}} \quad \underline{\mathrm{I}} \\
\mathrm{ca}-\text { qui } \\
\text { "K" usado para representar a sílaba toda "ca". }\end{array}$ \\
\hline
\end{tabular}

\subsubsection{Duas escritas silábicas justapostas}

Em cinco palavras, encontramos duas escritas silábicas justapostas. Dos seis entrevistados, quatro produziram escritas dessa maneira.

Tabela 7 - Exemplos de duas escritas silábicas justapostas.

\begin{tabular}{|c|c|}
\hline \multicolumn{2}{|c|}{ Duas escritas silábicas justapostas } \\
\hline Anália (escrita no computador) & $\begin{array}{l}\underline{\text { Al }} \underline{\text { QI }} \\
a-i-q-i, c a-q u i\end{array}$ \\
\hline $\begin{array}{l}\text { Eliane (escrita manual } \\
\text { e no computador) }\end{array}$ & $\frac{\text { VA V A }}{\text { uva }}$ \\
\hline Josefa (escrita manual) & 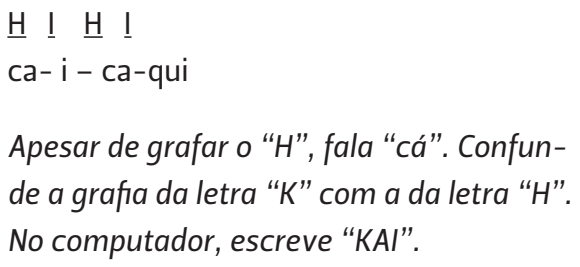 \\
\hline Josefa (escrita manual e no computador) & $\begin{array}{l}\underline{P} \underline{A} \underline{P} \underline{A} \\
\text { pe-a - pe-ra }\end{array}$ \\
\hline Rosevaldo (escrita no computador) & $\frac{A G}{a ́} \frac{A G}{\text { gua }}$ \\
\hline
\end{tabular}

\subsection{Análise entre palavras: a ocorrência de alternâncias grafo- fônicas}

Analisaremos agora os pares de palavras escritas manualmente e no computador para verificar a ocorrência de alternâncias grafofônicas, tais como encontradas por Molinari (2007).

\subsubsection{Alternâncias grafo-fônicas $1 / 1$}

De acordo com Molinari (2007), é possível identificar um primeiro tipo de alternância grafo-fônica com a qual uma mesma sílaba é grafada: primeiramente, uma única das letras possíveis 
e, em seguida, com outra letra possível (alternância grafo-fônica de uma letra para outra letra, ou 1/1). Encontramos esse tipo de alternância grafo-fônica de 1/1 em quatro pares de palavras, ocorrendo em mais de um segmento em dois deles:

Tabela 8 - Exemplos de alternâncias grafo-fônicas 1/1.

\begin{tabular}{|c|c|c|}
\hline \multicolumn{3}{|c|}{ Alternâncias grafo-fônicas 1/1 } \\
\hline $\begin{array}{l}\text { Benedita (escrita manual) } \\
\qquad \frac{\text { B T E N A }}{\text { betoneira }}\end{array}$ & $\begin{array}{l}\text { Benedita } \\
\text { (no computador) } \\
\qquad \underline{\mathrm{B}} \underline{\mathrm{TI}} \underline{\mathbf{N}} \underline{\mathrm{A}} \\
\text { be -to -ne-ra }\end{array}$ & $\begin{array}{l}\text { Alternância grafo-fônica 1/1 na } \\
3^{a} \text { sílaba "ne" - E/N. }\end{array}$ \\
\hline $\begin{array}{l}\text { Josefa (escrita manual) } \\
\qquad \begin{array}{l}\underline{\mathbf{A}} \underline{\mathbf{P}} \quad \underline{\mathbf{A}} \\
\text { ta }- \text { pio }-\mathrm{ca}\end{array}\end{array}$ & Josefa (no computador) & $\begin{array}{l}\text { Duas alternâncias grafo-fônicas } \\
\text { 1/1: } \\
\text { - na 2ª sílaba "pi" - P/I; } \\
\text { - na 4ª sílaba "ca" - A/Q (consi } \\
\text { deran do que nomeia o "Q" como } \\
\text { "cá"). }\end{array}$ \\
\hline $\begin{array}{l}\text { Rosevaldo (manual) } \\
\qquad \begin{array}{l}\underline{\mathrm{TA}} \underset{\mathrm{PI}}{\underline{\mathbf{A}}} \\
\text { ta - pio - ca }\end{array}\end{array}$ & $\begin{array}{c}\text { Rosevaldo (computador) } \\
\underline{\mathrm{I}} \underline{\mathrm{P}} \underline{\mathrm{Q}} \underline{\mathbf{H}} \\
\text { ta - pi - o-ca } \\
\text { Grafou o Q , mas chamou } \\
\text { de O. Grafou H, mas cha- } \\
\text { mou de } K \text {. }\end{array}$ & $\begin{array}{l}\text { Alternância grafo-fônica 1/1 na 4a } \\
\text { sílaba "ca" - A/H (considerando } \\
\text { que nomeia o "H" como "cá")2. }\end{array}$ \\
\hline $\begin{array}{l}\text { Rosevaldo (manual) } \\
\qquad \begin{array}{c}\underline{\mathrm{HA}} \underline{\mathbf{C}} \\
\text { ca - qui }\end{array}\end{array}$ & $\begin{array}{l}\text { Rosevaldo (computador) } \\
\qquad \begin{array}{c}\underline{\mathrm{K}} \quad \underline{\mathrm{I}} \\
\mathrm{ca}-\text { qui }\end{array}\end{array}$ & $\begin{array}{l}\text { Alternância grafo-fônica 1/1 na 2a } \\
\text { sílaba "qui" - C/I (ainda que, orto- } \\
\text { graficamente, a letra "C" não seja } \\
\text { pertinente para grafar o fonema / } \\
\text { qui/) }{ }^{3} \text {. }\end{array}$ \\
\hline
\end{tabular}

\subsubsection{Alternâncias grafo-fônicas $1 / 2$ ou $2 / 1$}

Molinari (2007) identificou um segundo tipo de alternância grafo-fônica frequente em escritas de crianças silábicoalfabéticas, no qual um segmento silábico da mesma palavra é grafado com letras pertinentes, aparecendo apenas uma delas na primeira escrita e mais de uma na segunda escrita (ou vice-versa). Encontramos essa alternância grafo-fônica de $1 / 2$ ou 2/1 em oito
2. Esse par apresenta outras alternâncias grafo-fônicas do tipo 2/1 que serão analisadas logo na sequência.

3. Idem. 
pares de palavras, ocorrendo em mais de um segmento em um deles:

Tabela 9 - Exemplos de alternâncias grafo-fônicas 2/1 ou 1/2.

\begin{tabular}{|c|c|c|}
\hline \multicolumn{3}{|c|}{ Alternâncias grafo-fônicas $2 / 1$ ou $1 / 2$} \\
\hline Anália (escrita manual) & Anália (no computador) & \\
\hline $\begin{array}{l}\text { CO MEA I } \\
\text { to - ma - te }\end{array}$ & $\begin{array}{l}\underline{\mathrm{TO}} \underline{\mathbf{M}} \underline{\mathrm{I}} \\
\text { to - ma - te }\end{array}$ & $\begin{array}{l}\text { Alternância grafo-fônica 2/1 na } \\
2^{a} \text { sílaba "ma" - MA/M. }\end{array}$ \\
\hline Eliane (escrita manual) & Eliane (no computador) & \\
\hline $\begin{array}{l}\underline{\mathrm{B}} \underline{\mathrm{TO}} \underline{\mathrm{R}} \underline{\mathrm{A}} \\
\mathrm{bi} \text { - tor - ne - rea }\end{array}$ & $\begin{array}{l}\underline{P} \underline{\mathbf{T}} \underline{\mathrm{A}} \\
\text { bi- tor-ne-rea }\end{array}$ & $\begin{array}{l}\text { Alternância grafo-fônica 2/1 na } \\
2^{\text {a }} \text { sílaba "to" - TO/T. }\end{array}$ \\
\hline Eliane (escrita manual) & Eliane (no computador) & \\
\hline $\begin{array}{l}\underline{\mathrm{I}} \underline{\mathrm{M}} \underline{\mathrm{T}} \\
\mathrm{t}-\mathrm{u}-\mathrm{mea}-\mathrm{te}\end{array}$ & $\begin{array}{c}\text { I } \underline{\text { MA }} \\
\text { t-u - mate }\end{array}$ & $\begin{array}{l}\text { Alternância grafo-fônica 1/2 na } \\
2^{a} \text { sílaba "ma" - M/MA. }\end{array}$ \\
\hline $\begin{array}{l}\text { Rosevaldo (manual) } \\
\qquad \underline{\text { BI }} \underline{\text { TO }} \underline{L} \underline{A} \\
\text { bi - to - ne- ra }\end{array}$ & $\begin{array}{l}\text { Rosevaldo (computador) } \\
\qquad \begin{array}{l}\text { B } \underline{\mathbf{T}} \underline{\mathrm{NA}} \\
\text { bi - to - ne-ra }\end{array}\end{array}$ & $\begin{array}{l}\text { Alternância grafo-fônica 2/1 na } \\
1^{a} \text { sílaba "be" - BI/B e 2/1 na } \\
2^{a} \text { sílaba "to" - TO/T. }\end{array}$ \\
\hline $\begin{array}{l}\text { Rosevaldo (manual) } \\
\qquad \underline{\text { Cl }} \underline{\mathrm{M}} \underline{\mathrm{TU}} \\
\text { ci - men - tu }\end{array}$ & $\begin{array}{l}\text { Rosevaldo (computador) } \\
\qquad \begin{array}{l}\text { C } \underline{M} \underline{\mathrm{TU}} \\
\text { ci- men -tu }\end{array}\end{array}$ & $\begin{array}{l}\text { Alternância grafo-fônica 2/1 na } \\
1^{a} \text { sílaba "ci" - Cl/C. }\end{array}$ \\
\hline $\begin{array}{l}\text { Rosevaldo (manual) } \\
\qquad \underline{\mathbf{T A}} \underline{\mathbf{P} \mathbf{I}} \underline{\mathbf{A}} \\
\text { ta - pio - ca }\end{array}$ & $\begin{array}{l}\text { Rosevaldo (computador) } \\
\qquad \begin{array}{l}\underline{\mathbf{T}} \underline{\mathbf{P}} \underline{\mathrm{Q}} \underline{\mathrm{H}} \\
\text { ta }-\mathrm{pi}-\mathrm{o}-\mathrm{ca}\end{array}\end{array}$ & $\begin{array}{l}\text { Duas alternâncias grafo-fônicas } \\
\text { 2/1: } \\
\text { - na } 1^{\text {a }} \text { sílaba "ta" - TA/T; } \\
\text { - na } 2^{\text {a }} \text { sílaba "pi" - PI/P. }\end{array}$ \\
\hline $\begin{array}{l}\text { Rosevaldo (manual) } \\
\qquad \underline{\mathbf{T U}} \underline{\mathbf{M}} \underline{\mathrm{I}} \\
\text { to - ma - te }\end{array}$ & $\begin{array}{l}\text { Rosevaldo (computador) } \\
\qquad \begin{array}{l}\underline{\mathbf{I}} \underline{\mathrm{M}} \underline{\mathrm{T}} \\
\text { to- } \mathrm{ma}-\mathrm{te}\end{array}\end{array}$ & $\begin{array}{l}\text { Alternância grafo-fônica 2/1 na } 1^{\text {a }} \\
\text { sílaba "to" - TU/T. }\end{array}$ \\
\hline $\begin{array}{l}\text { Rosevaldo (manual) } \\
\qquad \begin{array}{c}\underline{\text { A }} \underline{\mathbf{C}} \\
\text { ca - qui }\end{array}\end{array}$ & $\begin{array}{l}\text { Rosevaldo (computador) } \\
\qquad \begin{array}{c}\mathbf{K} \quad \underline{1} \\
\text { ca - qui }\end{array}\end{array}$ & $\begin{array}{l}\text { Alternância grafo-fônica 2/1 na } \\
1^{a} \text { sílaba "ca" - HA/K (consideran- } \\
\text { do que nomeia o "H" como "ca"). }\end{array}$ \\
\hline
\end{tabular}

É curioso notar que o autor de cinco desses oito pares é Rosevaldo. Com a exceção das escritas produzidas por Eliane para 
"tomate", todas as outras são do tipo 2/1 e "perdem" a vogal quando digitadas no computador.

\subsubsection{Alternâncias grafo-fônicas ortográficas}

Finalmente, há um terceiro tipo de alternância grafo-fônica identificado por Molinari (2007): as alternâncias grafo-fônicas ortográficas, nas quais, das possíveis opções ortográficas (convencionais ou não) para um segmento silábico da mesma palavra, aparece uma delas na primeira escrita e outra na segunda escrita.

Nas escritas produzidas pelos adultos neste estudo, encontramos dois pares com alternâncias grafo-fônicas ortográficas:

Tabela 10 - Exemplos de alternâncias grafo-fônicas ortográficas.

\begin{tabular}{|c|c|c|}
\hline \multicolumn{3}{|c|}{ Alternâncias grafo-fônicas ortográficas } \\
\hline $\begin{array}{c}\text { Benedita (manual) } \\
\underline{\mathbf{S}} \underline{\mathrm{M}} \underline{\mathrm{A}} \underline{\mathrm{N}} \underline{\mathrm{T}} \\
\text { ce-me-a- ne-to, cimento }\end{array}$ & $\begin{array}{l}\text { Benedita (no computador) } \\
\qquad \begin{array}{l}\text { C } \underline{\text { M I }} \underline{ } \\
\text { ci-men-to }\end{array}\end{array}$ & $\begin{array}{l}\text { Alternância grafo-fônica } \\
\text { or-tográfica na } 1^{\text {a }} \text { sílaba } \\
\text { "ci"- S/C. }\end{array}$ \\
\hline $\begin{array}{l}\text { Lourivaldo (manual) } \\
\qquad \underline{\text { LA } \underline{\text { JI }}} \\
\text { le-a-la ji-i-ji, laji }\end{array}$ & $\begin{array}{l}\text { Lourivaldo (no computador) } \\
\qquad \underline{\text { LA }} \underline{\mathbf{G E}} \\
\text { le-a-la ge, lage }\end{array}$ & $\begin{array}{l}\text { Alternância grafo-fônica } \\
\text { or-tográfica na 2ª́laba } \\
\text { "je" - JI/GE. }\end{array}$ \\
\hline
\end{tabular}

\subsection{Leitura X decodificação}

Observando a realização da tarefa pelos adultos e de tarefas similares por crianças ${ }^{4}$, podemos concluir que os adultos, em geral, são mais presos à decodificação das letras. Ao pedir que lessem, alguns falavam o nome das letras (Anália, Josefa e Rosevaldo), e o entrevistado que aprendeu a soletrar na escola quando criança (Lourivaldo) primeiramente soletrou e, depois, disse a palavra que acabara de escrever.

4. Podemos tomar como exemplo as crianças que aparecem no vídeo "Construção da escrita: primeiros passos", do Programa de Formação de Professores Alfabetizadores (PROFA), realizado pelo Ministério da Educação, em 2001, ou, mais recentemente, no vídeo "Pensando em voz alta", do Programa Ler e Escrever, da Secretaria da Educação do Estado de São Paulo.

Anália, Benedita e Rosevaldo também procedem da mesma maneira. Essa é uma diferença em relação às crianças. 
Aparentemente, os adultos percebem as contradições entre o que estão falando e o que estão escrevendo, mas isso não significa que saibam resolvê-las.

\subsection{Um caso particular: a "leitura" e a escrita de seu Lourivaldo}

Dos seis entrevistados, Lourivaldo é o que conseguia escrever as listas de forma mais eficiente. Porém, não conseguia ler nenhuma das palavras que acabava de grafar, sem antes soletrar as letras. Não procedia da mesma maneira que os adultos apontados no item anterior porque não dizia o nome das letras. Ele soletrava, pronunciando as letras de duas em duas, seguidas da sílaba que juntas supostamente elas formavam. Apesar de soletrar com muita agilidade, se atrapalhava quando se deparava com sílabas compostas por três letras.

Tabela 11 - Exemplos de escrita e soletração.

\begin{tabular}{|c|}
\hline $\begin{array}{c}\underline{A} \underline{\mathrm{R} I E} \underline{\mathrm{A}} \\
\mathrm{a}-\mathrm{rê}-\mathrm{i}-\mathrm{e}-\mathrm{a} \text {, areia }\end{array}$ \\
\hline$\frac{\underline{\mathrm{PER}} \underline{\mathrm{DA}}}{\text { pe-e-re-pe de-a-dá, pedra }}$ \\
\hline$\frac{\text { VI } \underline{\text { GAH }}}{\text { ve-i-vi gue-a-gá, viga }}$ \\
\hline$\frac{\underline{\mathrm{RA}} \quad \underline{\mathrm{LO}}}{\text { re-a-ra le-o-lo, ralo }}$ \\
\hline
\end{tabular}

De acordo com o que ele próprio afirmou na entrevista, tal procedimento servia para que conseguisse decodificar "palavras meias pequenas", mas isso era insuficiente para que conseguisse ler e escrever palavras com ditongos, encontros consonantais e dígrafos, além de frases, versos ou pequenos textos.

Sua agilidade em soletrar Ihe conferia uma "leitura" de palavras que parecia acontecer numa outra língua - como aquela brincadeira de falar na "língua do P". Isso nos impressionou tanto que resolvemos propor tarefas de leitura diferentes das apresentadas para os demais entrevistados. 
Sabendo que Lourivaldo havia sido cantor e compositor de letras de forró, solicitamos que ele escrevesse o refrão de uma de suas canções, primeiramente à mão e, depois, no computador.

Tabela 12 - Escritas de versos de uma música.

Mineira, chega pra cá calanguiar
Mineira, é da poeira levantar
MNENRA o cabra na zabumba dá
Mineira,
Escrita no computador
chega pra cá calanguiar

Na leitura, o procedimento de soletração o impediu de recuperar o sentido das escritas mais extensas. Transcrevemos abaixo sua tentativa de ler a seguinte manchete no jornal: "Com nova lei, número de divórcios bate recorde":

Lourivaldo: Cê-ó, có me, com. Nê-o, no. Vê-a, vá. Com nova. Lê-é, lé, i. Lei. Com nova lei. Nê-u, nu. Mê-é, me. Rê-o, ro. Número. Com nova lei número. Dê-é, de. Dê-i, di. Vê-o, vo ... divorcióis. Dê-a, da. Tê-a, ta. Data. Rê-e, re. Cê-o, co. Rê. Dê-e, de. Correta.

Entrevistadora: Recorde.

Lourivaldo: Recorde.

Entrevistadora: 0 senhor entendeu o que está dizendo aí?

Lourivaldo: É... essa notícia aí tá falando da TV Record, né?

Entrevistadora: E o que mais? 0 que está dizendo na primeira linha?

Lourivaldo: Cê-ó, có me, com. Nê-o, no. Vê-a, vá. Renova. Lê-é, lé, i. Lei. Renovando a lei.

Entrevistadora: Então, sobre o que deve ser essa notícia? 
Lourivaldo: Essa notícia assim, renovando a lei... pode ser a lei brasileira, né? Pode ser que a Record esteja filmando ou qualquer coisa assim... né?

Conforme nos contou durante a entrevista, durante o pouco tempo que frequentou a escola, foi intensamente treinado "no $A B C$ ", tendo a palmatória como "incentivo" maior para aprender a fazer o que a professora lhe ordenava. Apesar de ter sido um bom aluno - já que até hoje não se esquece do que e como aprendeu Lourivaldo, à sua maneira, tem tanta consciência de que não sabe ler e escrever com fluência que voltou a estudar aos 56 anos.

Ele é, como milhares de brasileiros foram e alguns ainda são, produto (ou vítima?) de um ensino fundamentado na concepção de que a escrita é um "código de transcrição gráfica de unidades sonoras", conforme explica Ferreiro:

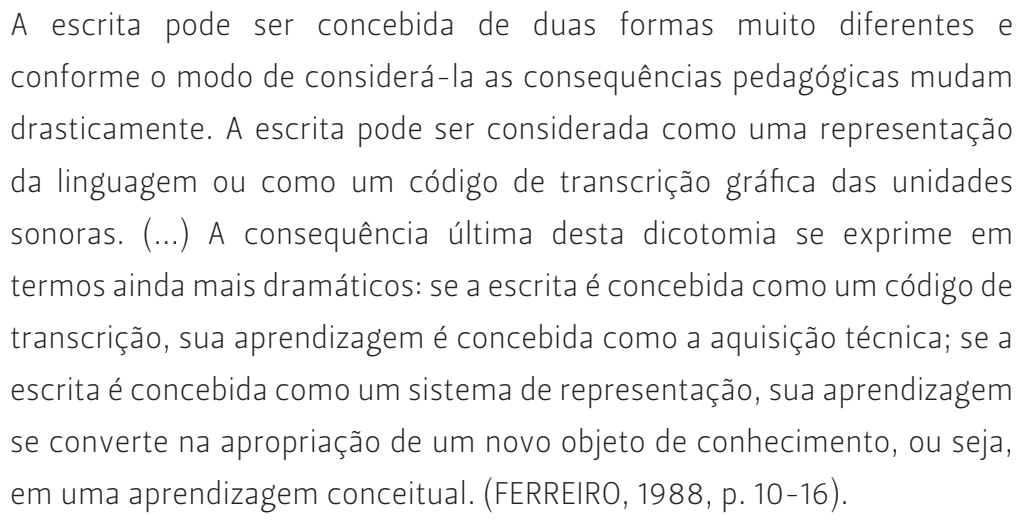

Lourivaldo é um exímio decodificador. No entanto, não se apropriou conceitualmente da escrita alfabética como sistema de representação. É, portanto, um analfabeto - apesar de ter conseguido escrever de forma convencional praticamente todas as palavras da lista ditada.

\subsection{Assinar é uma coisa, escrever o nome próprio é outra}

Os seis entrevistados escreveram o nome próprio de maneiras diferentes no caderno e no computador. Na realidade, no caderno, eles reproduziram a assinatura, mas, no computador, escreveram seus respectivos nomes de fato. 
Tabela 13 - Assinatura e escrita do nome próprio.

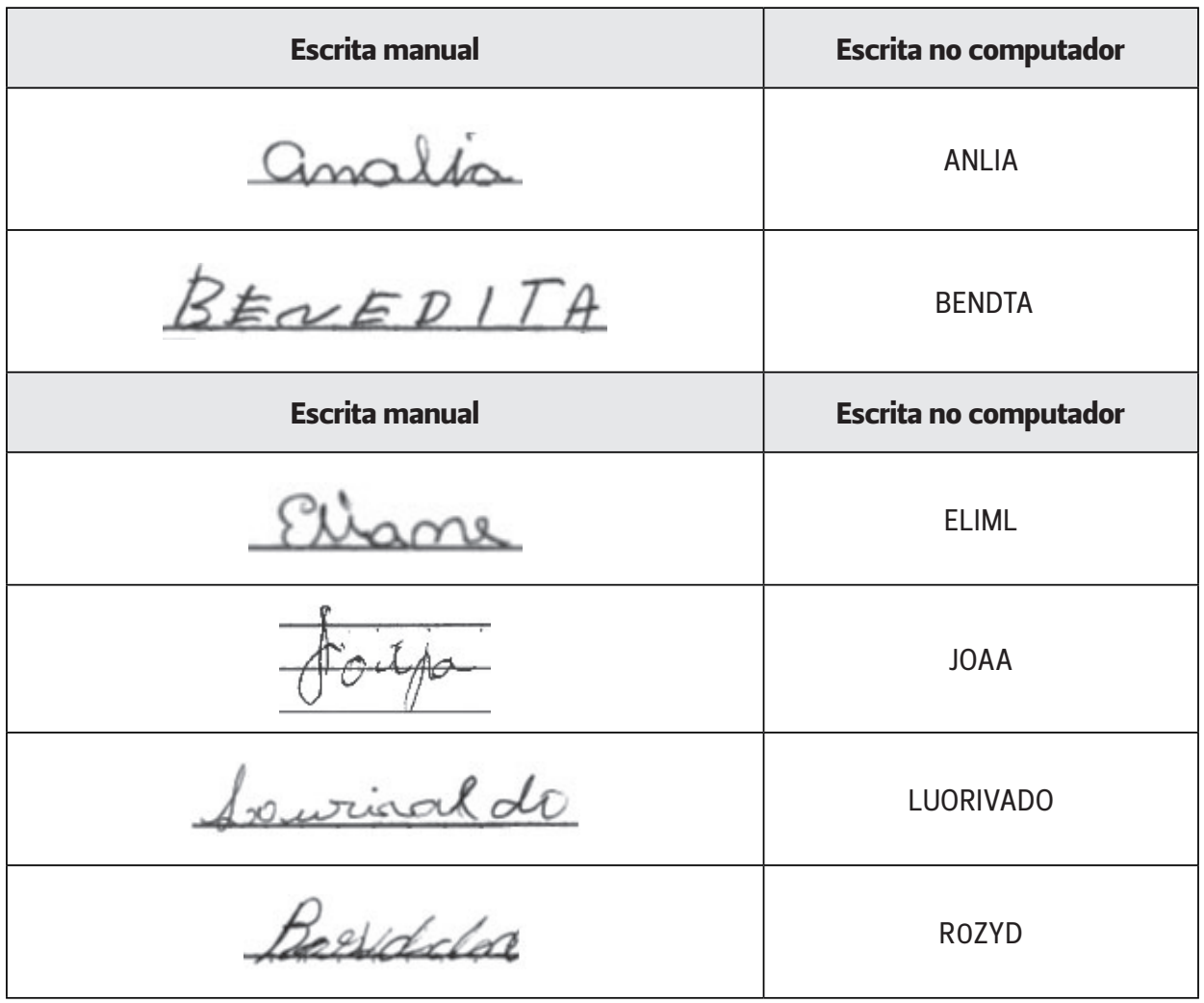

Dos seis entrevistados, cinco escreveram manualmente seu nome com letra cursiva. Apenas Benedita utilizou maiúsculas de imprensa. Josefa e Rosevaldo omitiram uma letra na escrita manual do primeiro nome.

Nas escritas do nome próprio no computador, Anália e Lourivaldo foram os que mais se aproximaram da escrita convencional de seus nomes. Nos demais, a escrita silábicoalfabética predominou. Sobretudo no início dos nomes, as consoantes e as vogais pertinentes apareceram em ordem. Da terceira ou quarta letra em diante, prevaleceu uma escrita silábica com valor sonoro convencional (Rosevaldo, Benedita e Josefa) e sem valor sonoro convencional (Eliane).

De acordo com a antropóloga Béatrice Fraenkel (1995), pesquisadora da história da assinatura, a ação de assinar está relacionada ao papel e às responsabilidades jurídicas do indivíduo na sociedade, e não necessariamente à leitura e à escrita ou à alfabetização.

Assim como aconteceu na história cultural do Ocidente, para os adultos entrevistados neste estudo, a assinatura também representa uma experiência à parte que não é "a da escrita nem a da leitura" (FRAENKEL, 1995, p. 81). Saber assinar o próprio nome 
não significa que se sabe escrever ou ler o próprio nome - nem qualquer outro texto.

Porém, para o Estado e também para algumas dessas pessoas, saber assinar o próprio nome, sobretudo na carteira de identidade, é o que lhes define como sujeitos alfabetizados - uma vez que aqueles que não conseguem assinar carregam nesse documento a inscrição "não alfabetizado" e precisam carimbar a digital em substituição da assinatura.

Lourivaldo é quem confirma que saber assinar é o que lhe confere o status de alfabetizado:

Eu só te digo uma coisa: eu não me considero analfabeto legítimo porque eu assino meu nome. Se eu não assinasse meu nome, acho que me consideraria analfabeto. Acho, não. Tenho certeza. Eu me consideraria um analfabeto legítimo.

Conforme apontamos no item anterior, saber decodificar não é condição suficiente para estar alfabetizado, assim como também não é suficiente saber assinar ou desenhar o nome próprio - ainda que alguns entrevistados pensem o contrário.

\section{Conclusões}

"Respeitar a realidade dos alunos." Talvez esse seja um dos mais pronunciados clichês na alfabetização de adultos. Fundamenta-se no trabalho de Paulo Freire, mas observamos que tem sido apropriado e praticado de forma equivocada por alguns educadores. Em primeiro lugar, temos visto, em alguns casos, um falso respeito à realidade popular concreta, na postura de educadores que encenam valorizar aquilo que na verdade não valorizam, incluindo a maneira como os alunos se vestem, falam, o que trazem como experiência vivida, o lugar onde moram, o trabalho por meio do qual se sustentam. Em segundo lugar, uma total ausência de consideração pela bagagem intelectual do aprendiz adulto à qual se refere Ferreiro (1983, p.2).

\footnotetext{
no será posible considerar uma acción alfabetizadora que tome como punto de partida lo que estos adultos saben, em lugar de partir de lo que ignoran? No será acaso nuestra propia ignorancia acerca de los sistemas de conceptos de estos adultos lo que nos lleva a tratarlos como si fueran ignorantes? (FERREIRO, 1983, p. 143).
}

Podemos concluir, portanto, como uma primeira implicação pedagógica resultante deste estudo a necessidade de reconhecer 
o que já sabem os alunos adultos sobre a língua escrita para, com base nisso, planejar as situações didáticas mais adequadas. É comum encontrarmos alunos da alfabetização de adultos queixando-se de que não conseguem escrever porque "comem letras". Além de terem consciência de que faltam letras para que suas escritas se assemelhem às grafias convencionais, provavelmente ouviram isso dos educadores que tentaram alfabetizá-los. Na realidade, considerando a aquisição do sistema alfabético de escrita como um processo, não estão comendo ou tirando letras, estão agregando letras a uma escrita que parte da hipótese silábica rumo à escrita alfabética.

Ter clareza dos detalhes do processo de aquisição do sistema de escrita confere ao professor subsídios para que possa interpretar adequadamente a escrita dos alunos e, consequentemente, avaliar se houve ou não avanços de fato. As escritas silábico-alfabéticas, bem como as soluções de compromisso que foram anteriormente encontradas em produções infantis e que neste estudo encontramos em produções adultas, são escritas muito estranhas e irregulares, se comparadas com o período anterior da hipótese silábica com valor sonoro convencional no qual são produzidas escritas muito estáveis e fáceis de interpretar.

\footnotetext{
La importancia de conocer más profundamente este periodo no sólo se sostiene desde el punto de vista psicolinguistico sino también educativo. En la escuela, muchos de los niños que culminan su primer año escolar, habiendo logrado construir una hipótesis silábica o silábico-alfabética, son reprobados por ser considerados disléxicos, dada la sistemática omisión de letras em sus escrituras. Así, la caracterización de este momento, como un período normal del desarollo em la apropriación del principio alfabético de nuestro sistema de escritura constituye un ponto central de esta indagación (QUINTEROS, 1997, pp. 14-15).
}

Portanto, outra implicação pedagógica que destacamos como consequência da compreensão dessas estranhas escritas silábico-alfabéticas é o rigor com que se devem realizar as avaliações diagnósticas dos alunos que estão nessa fase independentemente da idade. É preciso ter muito cuidado para não interpretar as desordens, as alternâncias, os recheios gráficos ou coringas como evidências de um retrocesso. Conforme a própria Emilia Ferreiro (2009) alerta, "omissões e desordem são dois elementos clássicos do diagnóstico de dificuldade de aprendizagem", mas podem representar, na realidade, uma dificuldade do professor em avaliar, e não do aluno em aprender. Essa clareza na interpretação dessas escritas, por sua vez, 
confere ao professor possibilidades de planejamento de situações didáticas e intervenções mais acertadas. A escrita de listas de palavras dissílabas com letras móveis e em duplas de alunos com hipóteses próximas é um exemplo de situação didática adequada para esses casos. Os dissílabos representam um bom problema para as crianças que já escrevem segundo a hipótese silábica com valor sonoro convencional, seja com vogais, seja com consoantes pertinentes. Essas palavras geram um conflito entre os critérios de legibilidade que os alunos possuem nesse momento, levando em conta dois eixos de análise: um qualitativo e outro quantitativo. No eixo qualitativo, consideram que cada sílaba deve ser grafada com uma letra (em geral, a vogal) que não se deve repetir. No eixo quantitativo, não admitem ser possível escrever e ler uma palavra que seja formada por apenas duas letras (hipótese da quantidade mínima). Na tentativa de resolver essa tensão, as crianças constroem soluções pontuais, parciais, locais que as ajudam a avançar. E, por último, mas não menos importante, no caso de adultos, escritas convencionais de listas de palavras podem dar um falso diagnóstico, como observamos no caso de Lourivaldo. Sabe escrever palavras simples, mas não consegue recuperar o que escreveu, nem escrever frases, versos, nem ler manchetes de jornal. Assim como Lourivaldo, muitos adultos que participam de cursos de alfabetização já tiveram alguma experiência escolar no passado. Boa parte deles foi vítima de um ensino que concebe a língua como um código de transcrição e não como um sistema de representação. Com esses alunos, é preciso ajudar a superar essa necessidade de soletrar, ensiná-los a ler de verdade, a produzir sentido e não barulho com a boca.

Concluímos também que os adultos entrevistados nessa pesquisa produziram sim escritas silábico-alfabéticas com soluções pontuais semelhantes às encontradas nas escritas infantis em investigações anteriores.

Finalizamos este estudo fazendo nossas as palavras de Ferreiro: 


\section{REFERÊNCIAS}

FERREIRO, Emilia. Los adultos no alfabetizados y sus conceptualizaciones del sistema de escritura. Cuadernos de Investigaciones Educativas, Ciudad de Mexico, n.10, pp $120-$ 234, fev. 1983.

Cortez, 1988.

Reflexões sobre alfabetização. 13. ed. São Paulo:

La desestabilización de las escrituras silábicas:

alternancia y desorden con pertinencia. Lectura y Vida:

revista latinoamericana de lectura, La Plata, ano 30, n.2, pp 6-13, jun. 2009.

FERREIRO, Emilia; TEBEROSKY, Ana. Psicogênese da língua escrita. Traduzido por Diana Myrian Lichtenstein. Liana Di Marco, Mário Corso. Porto Alegre: Artmed, 1999, 304 p.

FRAENKEL, Béatrice. A assinatura contra a corrupção do escrito. In: BOTTÉRO, J. Cultura, pensamento e escrita. São Paulo: Ática, 1995.

MOLINARI, María Claudia. Estabilidad y variación de las palabras en los inicios de la alfabetización (escritura manual y con computadora). Tesis de Maestria del Departamento de Investigaciones Educativas del Centro de Investigación y de Estudios Avanzados del Instituto Politécnico Nacional, Mexico D.F. 2007.

Identidades y diferencias en la escritura en papel y en computadora en las primeras etapas del proceso de alfabetización. Lectura y Vida: revista latinoamericana de lectura, La Plata, ano 28, n.4, pp 18-30, dez. 2007.

QUINTEROS, Graciela. El uso y función de las letras en el periodo pre-alfabético. Tesis de Maestria del Departamento de Investigaciones Educativas del Centro de Investigación y de Estudios Avanzados del Instituto Politécnico Nacional, Mexico D.F. 1997. 